\title{
An adaptive annual rhythm in the sex of first pigeon eggs
}

\author{
Cor Dijkstra • Bernd Riedstra $\cdot$ Arjan Dekker • \\ Vivian C. Goerlich • Serge Daan • Ton G. G. Groothuis
}

Received: 6 August 2009/Revised: 29 March 2010 /Accepted: 1 April 2010/Published online: 21 April 2010

(C) The Author(s) 2010. This article is published with open access at Springerlink.com

\begin{abstract}
When the reproductive value of male and female offspring varies differentially, parents are predicted to adjust the sex ratio of their offspring to maximize their fitness (Trivers and Willard, Science 179:90-92, 1973). Two factors have been repeatedly linked to skews in avian offspring sex ratio. First, laying date can affect offspring sex ratio when the sexes differ in age of first reproduction, such that the more slowly maturing sex is overproduced early in the season. Second, position of the egg in the laying sequence of a clutch may affect sex ratio bias since manipulating the sex of the first eggs may be least costly to the mother. We studied both factors in two nondomesticated pigeon species. Both the Wood pigeon (Columba palumbus) and the Rock pigeon (Columba livia) have long breeding seasons and lay two-egg clutches. In the field, we determined the sex of Wood pigeon nestlings. In Rock pigeons, housed in captivity outdoors, we determined embryo sex after 3 days of incubation. On the basis of their sex-specific age of first reproduction, we predicted that males, maturing at older age than females, should be produced in majority early and females later in the year. This was confirmed for both species. The bias was restricted to first eggs. Rock pigeons produced clutches throughout the year and show that the sex of the first egg followed an annual cycle. To our knowledge, this study presents the first evidence of a full annual rhythm in adaptive sex allocation in birds. We suggest that this
\end{abstract}

Communicated by J. Graves

C. Dijkstra $(\bowtie) \cdot$ B. Riedstra $\cdot$ A. Dekker $\cdot$ V. C. Goerlich •

S. Daan · T. G. G. Groothuis

Behavioural Biology, University of Groningen,

P.O. Box 14, 9750 AA Haren, The Netherlands

e-mail: C.Dijkstra@rug.nl reflects an endogenous seasonal program in primary sex ratio controlled by a preovulatory mechanism.

Keywords Avian - Primary sex ratio - Sex allocation . Seasonal variation $\cdot$ Egg-laying sequence $\cdot$ Pigeon . Laying date

\section{Introduction}

If the fitness returns for sons and daughters vary with environmental conditions, parents are expected to adjust the sex ratio of their offspring to these conditions, as predicted by Trivers and Willard (1973) specifically for variation in maternal condition. Substantial evidence exists that a variety of factors can affect the proportion of sons and daughters in the progeny, and that in vertebrates with chromosomal sex determination, offspring sex ratios may deviate significantly from the expected parity (Hardy 2002). In birds, unlike mammals, the female is the heterogametic sex. Avian mothers thus have the potential to manipulate the future sex of her offspring prior to fertilization, since they develop gametes holding either the Z ("male") or W ("female") sex chromosome. Since the male solely provides the fertilizing $\mathrm{Z}$ sperm, sex determination occurs during meiosis inside the mother's body. Embryo development takes place outside the mother's body and only commences after oviposition and start of incubation. Since these processes take place soon after fertilization, the sex of the embryo and its physiological milieu provided by the mother can be determined close to fertilization. As a consequence, sex ratio biases in birds have been studied extensively. Their existence, potential functional consequences, and underlying mechanisms have been recently reviewed (Pike and Petrie 2003; Alonso-Alvarez 2006). 
Unfortunately, in spite of extensive research, studies on offspring sex ratios are not often replicated. In this study, we applied the same analyses to sex allocation in two closely related bird species. We focus on two covariates of biased avian offspring sex ratio: laying date and the position of the egg in the laying sequence of the clutch. We chose to do this study in two species of pigeon for three reasons. First, pigeons have long natural reproductive seasons, enabling a thorough analysis of seasonal changes. Second, pigeons typically lay two-egg clutches allowing a simple comparison between the first and the second egg. Third, ever since Aristotle, pigeons have repeatedly been attributed the remarkable habit of laying one male and one female egg per clutch (see below).

With respect to laying date, it was hypothesized before that if one sex requires a longer maturation period than the other, it should have an advantage when born early in the year, and mothers should anticipate this by producing the slowly maturing sex when breeding early and the faster maturing sex when breeding late (Dijkstra et al. 1990). Evidence for seasonal variation in offspring sex ratio has been found in several species (e.g., Howe 1977; Dijkstra et al. 1990; Daan et al. 1996; Smallwood and Smallwood 1998; Andersson et al. 2003; Eraud et al. 2006; Husby et al. 2006; Weatherhead 2009). Theoretical models have expanded the functional explanation given to general sex differentiation in the dependence of fitness on date of birth (Daan et al. 1996; Pen et al. 1999). The expected relation between seasonal variation in offspring sex ratio and sexspecific age of first reproduction has been examined and confirmed only in the kestrel, Falco tinnunculus (Dijkstra et al. 1990). All of these studies concerned species with a short season of up to circa 2 months in which clutches are started. Pigeons offer the opportunity to cover a much wider range of laying dates and thus to gain an impression of annual rhythmicity in sex ratio bias. They have a long breeding season and produce several clutches each year. When food conditions are favorable, feral pigeons even show year-round reproduction (Johnston and Janiga 1995). In feral pigeons, males are recruited to the breeding population at an older age than females (Johnston and Janiga 1995). We therefore expected on the basis of the sex-specific maturation hypothesis that nests produced early in the year should be male biased: Early born males would have the advantage of a long time to mature till the next breeding season. Females reproduce at a younger age (Johnston and Janiga 1995), and consequently, late nests are expected to be female biased.

With respect to the laying sequence of the eggs, there are two reasons for expecting a relationship between the sex of the embryo and the position in the laying sequence of the respective egg. Firstly, sons and daughters may differ in growth and competitive ability (Jones et al. 2009). The mother may adjust the playing field for sex-specific sibling competition by adjusting the sequence with which the sexes hatch, since earlier hatching chicks have a size advantage over later ones. In birds, hatching order depends on laying order of the eggs in a clutch, and a laying order-dependent sex bias has repeatedly been demonstrated in avian species (e.g., Ankney 1982; Dijkstra et al. 1990; Nager et al. 2000; Arnold and Griffiths 2003; Badyaev et al. 2003; Carranza 2004; Lezalova et al. 2005). Secondly, it has been hypothesized that manipulation of the sex of the offspring by differential abortion of follicles of the unpreferred sex would be less costly in first eggs of the clutch than in later laid eggs. This is because replacement of follicles aborted after laying the first egg may have substantial costs. It would induce either laying gaps, since time is needed for maturation of the next follicle, or incompletely yolked eggs. Therefore, a sex bias would be expected especially in the first egg of the clutch (Emlen 1997).

The pigeon provides an excellent model to study both the effect of season and laying order on primary sex ratio. First, pigeons almost always produce a clutch size of only two eggs which are usually laid with an interval of $44 \mathrm{~h}$ (Johnston and Janiga 1995). This predictable pattern and the small clutch size render the species suitable for sex ratio studies. It is widely believed that the pigeon is capable of allocating sons to first and daughters to second eggs, opening the possibility of an extreme sex allocation strategy. More than two millennia ago, Aristotle wrote, "The pigeon, as a rule, lays a male and a female egg, and generally lays the male egg first" (Aristotle, about 350 B.C.). Several authors later expressed the same view of nonrandom sex allocation in pigeons (e.g., Darwin 1874, p. 263; Starr 1886; Fulton and Lumley 1895, p. 38; Riddle 1919). This general belief was persistent, even though no convincing evidence was published. Furthermore, during the early decades of the twentieth century, large data sets from breeds of domesticated pigeons (Columba livia domestica) reported that among nests of two young, 50\% were mixed-sex broods, as expected with random sex determination (Cole and Kirkpatrick 1915; Oguma 1927; Levi 1945). However, Riddle (1919) suggested that the unbiased frequencies of mixed-sex broods in these studies may be due to domestication.

Recent work suggests that domestic pigeons can indeed change the primary sex ratio of their offspring: A study on domesticated homing pigeons $C$. livia domestica reported that a combination of food restriction and repeated egg production, leading to a decrease in maternal body mass, induced a female-biased sex ratio of embryos after repeated re-laying (Pike 2005). Goerlich et al. (2009) showed that testosterone treatment of the mother promoted the production of male embryos. Both food availability and maternal hormone production are likely to change in the course of the year (Wingfield and Farner 1993) and may well lead to 
seasonal effects on offspring sex ratio. In both studies mentioned above, it was the first egg that showed a biased sex ratio and not the second egg. This opens the intriguing possibility that laying date interacts with laying order, an effect found in the mourning dove (Zenaida macroura, Edmunds and Ankney 1987).

Based on the hypothesis of sex-specific maturation (i.e., age of first reproduction), we predicted that wild pigeon species should overproduce sons early in the season and daughters later in the season as observed in the kestrel (Dijkstra et al. 1990). Based on the above-mentioned considerations by Emlen (1997) and the studies by Pike (2005) and Goerlich et al. (2009), we also expected that this seasonal change in sex ratio would be most strongly present in the first egg of a clutch. To test these predictions, we investigated data indicative for the primary sex ratio in two related Columba species, the Wood pigeon (Columba palumbus), under natural conditions, and the ancestor of the domesticated species, the Rock pigeon $(C$. livia $)$, in captivity outdoors.

\section{Materials and methods}

\section{The Wood pigeon field study}

The field study was performed on the Wood pigeon $(C$. palumbus) in 1996 and 2001, in the provinces of Groningen and Drenthe in the north of the Netherlands. From February until October, the study area was monitored regularly for Wood pigeon nests. In each nest, eggs were individually marked with a non-toxic marker. On the first visit after hatching, a blood sample $(15 \mu \mathrm{l})$ was taken from the ulnar vein of each squab. Samples were stored in ethanol and kept at $4^{\circ} \mathrm{C}$ until molecular sex determination.

To validate the assumption that the largest squab was the first hatched chick from the first laid egg, we used a subset of 14 nests in which we were able to accurately determine laying sequence of both eggs. These nests contained only one fresh egg during one visit but also the second egg at the next visit. Frequent monitoring of these nests around hatching allowed us to establish hatching sequence of egg 1 and egg 2 of the clutch. The hatchlings were individually marked by clipping a toenail. We checked the nests once per 3 days and monitored growth of both nestlings by measuring wing length (to the nearest millimeter), until the eldest nestling reached the age of 18 days, since older young tended to fledge prematurely when handled. In order to check whether wing length was a reliable estimator of hatching rank and laying order of the eggs, we monitored in detail the hatching and subsequent wing length growth of the siblings in the 14 nests mentioned above. In all the 14 nests, hatching sequence within the clutch reflected laying sequence of the eggs. The average time interval of hatching between both eggs was approximately 1 day $(1.07 \pm 0.4$ day, $n=14$ ). The ranking of wing length between both siblings measured in the first week of the nestling stage $(n=13$, one nest lost one chick), as well as shortly before fledging ( $n=$ 12 , another nest lost one chick), was a $100 \%$ reliable indicator of the laying sequence of both eggs in the clutch. We confirmed this reliability of the wing length measurement in a larger sample of nests, in which wing length ranking of the siblings early in the nestling stage remained stable until shortly before fledging in 53 out of 54 broods. Our measurements clearly assure that wing length ranking of Wood pigeon siblings reflects egg-laying order. Nestling growth data of the subset of 14 nests were further used to back-calculate the laying dates from those broods that were detected only after hatching of the chicks. Using the 14 nests with known laying date, back calculation from the nestling wing length data revealed an estimate of laying date of the first egg of the clutch with accuracy of \pm 1 day.

Since we were interested in the effects of laying sequence/ nestling rank within the brood, our data analysis was performed on the typical clutch size of two eggs/nestlings. For the Wood pigeons, this included $81.1 \%$ of all 312 broods. The remaining $18.9 \%$ were broods of one nestling, of which 27 were male and 32 were female. For these nests, we had no indication on rank order of the solitary nestling present, and these nests were omitted from the analysis of nestling rank order effects.

\section{The Rock pigeon aviary study}

To investigate annual primary sex ratio variation in detail, we embarked on a study with the Rock pigeon. This species reproduces easily in captivity, has an extremely long breeding season, and is the ancestor of all domesticated C. livia pigeons. The birds were kept in an outdoor aviary, enabling frequent nest controls and establishment of laying order of the eggs within a clutch, as well as the sex of the embryos shortly after clutch completion. Although details on reproductive timing in natural populations of Rock pigeons are lacking, such data are available for its direct descendant, the feral pigeon. Feral pigeons are characterized by an extended laying season of 8 to 10 months and can reproduce year-round when food is available in excess (Johnston and Janiga 1995). Twenty-four male and 24 female Rock pigeons were obtained from a private breeder and color-ringed for individual recognition. All birds were descendants from two populations, from the isle of Crete and from the Belgian Ardennes. The pigeons were housed at the Zoological Laboratory in Haren in a large outside aviary (length $\times$ breadth $\times$ height $=12 \times 4 \times 2.5 \mathrm{~m}$ ) with a shelter containing 25 nest-boxes. From April 1, 2001 onwards, nest-bowls and nesting material were provided. Pairs occupying the nest-boxes were identified, and we moni- 
tored nest building and subsequent egg laying by daily checks. The eggs were marked in the order of laying and according to laying date with a permanent marker.

We induced laying of multiple clutches in order to obtain sufficient data of repeated clutches of individual females over the whole season and to mimic the field situation, where relaying after nest predation is common (Johnston and Janiga 1995). To do so, we adopted the following protocol: after laying of the second egg, the eggs were left to be incubated by the parents for 3 days to allow sufficient embryo development for molecular sex determination. Then, both eggs were replaced with dummy eggs and stored at $-20^{\circ} \mathrm{C}$ until further processing. The two dummy eggs remained in the nest to be incubated for another 10 days, after which, they were removed. In this way, the pigeons were incubated 5 days shorter than the average incubation period of 18 days (Johnston and Janiga 1995), thereby avoiding the initiation of crop milk production which starts several days before egg hatching (Levi 1945). After removal of the dummy eggs, the pairs were left undisturbed until initiation of the following clutch, upon which the identity of the breeding pair was established again. The manipulation of the eggs was identical as in the first clutch. Data collection was terminated after almost three full years in December 2003.

The analysis of laying sequence and embryo sex in the Rock pigeons was performed on 239 clutches with two sexed embryos. In another 40 clutches in which only one embryo was successfully sexed, 21 were male and 19 were female.

\section{Sexing}

Molecular sex determination of blood samples (Wood pigeons) and embryonic tissue after 3 days of incubation by the parents (Rock pigeons) was performed by amplification of sex-specific gene sequences. DNA was extracted using the Chelex method (Walsh et al. 1991). Two microliters of the resulting DNA solution was used in a polymerase chain reaction to amplify part of the CHD-W gene in females and the CHD-Z gene in both sexes, applying primers P2 and P8 (Griffiths et al. 1996, 1998). After separation on a $2.5 \%$ agarose gel containing ethidium bromide, the size difference of the amplified products from the Z- and W-chromosome was visualized under UV light. Based on these results, embryos were identified as male (one band, CHD-Z product) or female (two bands, CHD-Z, respectively, CHD-W product).

\section{Statistical analysis}

Sex ratio data were analyzed using likelihood-ratio tests (binomial and G-test) as well as hierarchical linear models (MlwiN 2.02; Rasbash et al. 2005). Hierarchical models accommodate unbalanced data and take into account the nested relationships among data points, thereby preventing pseudoreplication.

For the Wood pigeon, we applied two-level hierarchical models with the individual nestlings (first level) nested within a clutch (second level). Predictor variables in these models were the wing length rank of the nestling within the brood (one or two, see "Materials and methods" described in part 1), the laying date of the first egg of the clutch (Julian date) which varied from early March until September and the interaction term between both. The dependent variable, offspring sex, being binomially distributed, was transformed using the logit link function and analyzed assuming a binomial error distribution at the level of the individual.

With respect to the Rock pigeon, multiple clutches could be reliably identified as belonging to individual pairs. Hence, three-level models were applied: the individual embryo (first level) nested within a clutch (second level) and multiple clutches nested within a pair (third level). Since the Rock pigeons produced clutches year-round for almost 3 years in total, we fitted models to the data assuming annual cyclic variation in sex ratio (i.e., with a period of 12 months). The cyclic variation of the data was tested by harmonic regression in a multiple regression analysis, using the CircWave software developed by R.A. Hut (Lincoln et al. 2006; Comas et al. 2008). We used as predictor variables, respectively, laying order of the egg within the clutch $(1$ or 2$)+[\operatorname{sine}(2 \times \pi \times$ month of laying/12)]+ [cosine $(2 \times \pi \times$ month of laying/12)] the two-way interactions. The potential cumulative effect of egg removal over a long period of 3 years on Rock pigeon sex ratios was tested by adding "year" to the statistical models, first, as a continuous predictor $(d f=1)$ and, alternatively, as categorical predictor $(d f=2)$. In both cases, the effect of "year" on the sex ratio was non-significant and was dropped from the final models. Since we were mainly interested in annual (withinyear) variation, the non-significant between-year effect was omitted from the tables as presented in the "Results" section.

In all models, parameters were estimated using secondorder quasi-likelihood estimation (Goldstein 1995). Nonsignificant predictors were eliminated from the complete model one by one by backward elimination, omitting the higher order two-way interactions first. Significance was tested using the Wald statistic, which follows a $\chi^{2}$ distribution. Results with $\alpha<0.05$ (two-tailed) were regarded as significant.

\section{Results}

The Wood pigeon

Egg laying by the Wood pigeons was initiated from March until September and peaked in June, July, and August (Table 1). Overall, among 506 nestlings from broods of two 
Table 1 Frequencies of different brood sex compositions and sex ratios (percent, $\delta^{\lambda} \delta^{\lambda}$ ) in Wood pigeon broods of two nestlings in the course of the year, categorized in monthly laying date intervals ( $n=253$ broods, 506 nestlings)

\begin{tabular}{|c|c|c|c|c|c|c|c|c|c|c|c|c|c|}
\hline \multirow[t]{2}{*}{ Brood composition } & \multicolumn{13}{|c|}{ Laying date (month) } \\
\hline & Jan & Feb & Mar & Apr & May & Jun & Jul & Aug & Sep & Oct & Nov & Dec & Total \\
\hline Male (1)-female (2) & & & 5 & 7 & 10 & 20 & 18 & 16 & 2 & & & & 78 \\
\hline Male (1)-male(2) & & & 4 & 5 & 12 & 13 & 13 & 9 & 2 & & & & 58 \\
\hline Female (1)-female (2) & & & 2 & 5 & 11 & 9 & 12 & 14 & 6 & & & & 59 \\
\hline Female (1)-male(2) & & & 2 & 1 & 7 & 13 & 10 & 19 & 6 & & & & 58 \\
\hline Total & & & 13 & 18 & 40 & 55 & 53 & 58 & 16 & & & & 253 \\
\hline Sex ratio & & & 57.7 & 50.0 & 51.3 & 53.6 & 50.9 & 45.7 & 37.5 & & & & 49.8 \\
\hline
\end{tabular}

Data were collected in the nestling stage, and nestlings were size-ranked (1 or 2) based on their wing length. Laying date of the first egg of the clutch was back-calculated (see "Materials and methods")

young, 252 (49.8\%) were male, which did not deviate from parity $\left(p_{\text {binom. }}=0.48\right)$, in accordance with expectation. When analyzing sex ratios among nestlings of rank 1

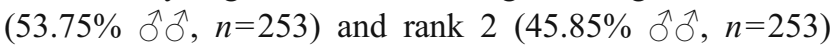
separately, neither of them differed significantly from $50 \%$ (rank $1, p_{\text {binom. }}=0.26$; rank $2, p_{\text {binom. }}=0.21$ ). The proportion of males did not differ significantly between rank 1 and rank 2 nestlings $\left(G_{1}=3.16, p=0.08\right)$. The combination of a rank 1 male nestling with a rank 2 female occurred most frequently (Table 1), but the overall frequency of the four different brood compositions with respect to sex of the

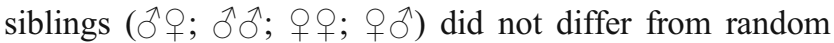
expectance $\left(G_{3}=4.39, p=0.22\right)$. This contrasts with the proposition originally due to Aristotle and repeatedly stated in the literature (see "Introduction").

We subsequently analyzed the relation between sex ratio and laying date. When combining rank 1 and 2, the overall sex ratios showed a negative but non-significant relationship with laying month of the clutch (coefficient $=-0.003$, Wald $\chi_{1}{ }^{2}=1.84, p=0.17$, Table 1). However, depending on the rank of the nestling, the sex ratio varied strongly and significantly in the course of the breeding season (interaction, laying month $\times$ nestling rank: $n=506$, Wald $\chi_{1}{ }^{2}=5.81$, $p=0.016$, Table 2 and Fig. 1). Post hoc tests revealed a

Table 2 Fitted parameters of a two-level model (nest-nestling) explaining Wood pigeon nestling sex ratios (logit link function), as predicted by $\mathrm{A}$ : within-brood nestling rank based on wing length difference (rank number 1 or 2 ) and $B$ : the month of laying of the clutch and the interaction between both predictors $(\mathrm{A} \times \mathrm{B})$

\begin{tabular}{lccc}
\hline Predictors & $B$ (coeff.) & Wald $\chi^{2}$ & $p$ \\
\hline Constant & 3.783 & & \\
A: Nestling rank number (1 or 2) & -2.126 & 7.539 & 0.0060 \\
B: Month of laying (1-12) & -0.516 & 7.593 & 0.0059 \\
A $\times$ B & 0.282 & 5.81 & 0.0160 \\
\hline
\end{tabular}

For fitted curves based on this model, see Fig. 1 significant decrease in the course of the proceeding breeding season in the proportion of males among nestlings of rank 1 $\left(n=253\right.$, Wald $\chi_{1}^{2}=7.71, p=0.005$, Fig. 1) and a nonsignificant positive seasonal change in the sex ratio of nestlings of rank $2\left(n=253\right.$, Wald $\chi_{1}^{2}=0.341, p=0.55$, Fig. 1$)$ in line with our predictions.

\section{The Rock pigeon}

The Rock pigeons produced clutches throughout the year, and the number of clutch initiations peaked from April to July, somewhat earlier than in the Wood pigeon. From September to December, during the main molting period, the number of clutches laid was at the lowest level (Table 3).

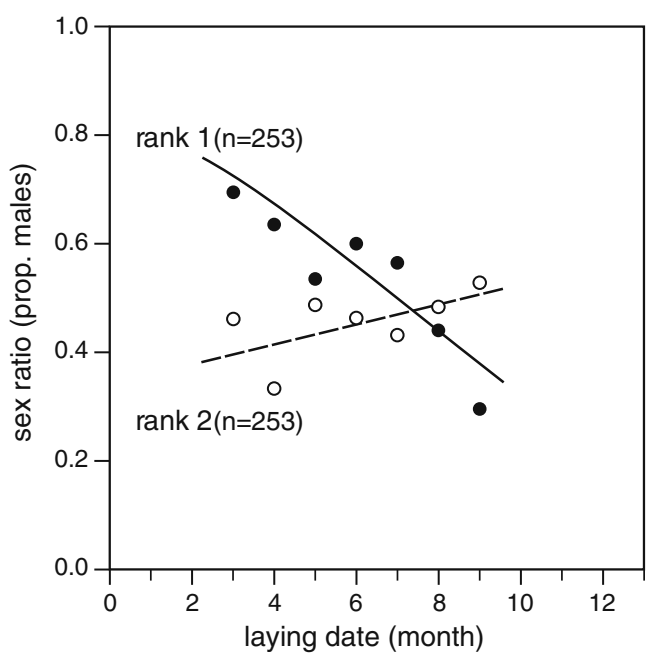

Fig. 1 Sex ratio (proportion males) of 253 Wood pigeon broods of two ( $n=506$ nestlings in total), as a function of month of laying of the first egg from the clutch, presented separately for the nestling with the larger (rank 1, $n=253$ ), respectively, the smaller wing length (rank 2, $n=253$ ), indicative of hatching sequence. Symbols represent monthly averages (March-September). Lines represent the fit of logistic regressions of sex on laying month, for rank 1 (solid line, $p<0.05$ ) and rank 2 (dashed line, n.s.). The seasonal trend of sex ratio was significantly different between both nestling ranks (see text) 
Table 3 Frequencies of different brood compositions (sex in relation to laying order) as well as sex ratios (percent, $\hat{\sigma} \hat{\delta}$ ) in clutches of captive Rock pigeons ( $n=239$ clutches, 478 sexed embryos), in the course of the year, categorized in monthly laying date intervals (data from April 2001 to December 2003)

\begin{tabular}{|c|c|c|c|c|c|c|c|c|c|c|c|c|c|}
\hline \multirow[t]{2}{*}{ Brood composition } & \multicolumn{13}{|c|}{ Laying date (month) } \\
\hline & Jan & Feb & Mar & Apr & May & Jun & Jul & Aug & Sep & Oct & Nov & Dec & Total \\
\hline Male (1)-female (2) & 2 & 0 & 8 & 10 & 9 & 8 & 7 & 0 & 1 & 1 & 0 & 1 & 47 \\
\hline Male (1)-male (2) & 2 & 5 & 9 & 9 & 12 & 17 & 8 & 3 & 2 & 1 & 0 & 1 & 69 \\
\hline Female (1)-female (2) & 5 & 3 & 5 & 6 & 5 & 9 & 8 & 6 & 3 & 6 & 0 & 2 & 58 \\
\hline Female (1)-male (2) & 3 & 1 & 4 & 9 & 10 & 8 & 13 & 8 & 3 & 2 & 4 & 0 & 65 \\
\hline Total & 12 & 9 & 26 & 34 & 36 & 42 & 36 & 17 & 9 & 10 & 4 & 4 & 239 \\
\hline Sex ratio & 37.5 & 61.1 & 57.7 & 54.4 & 59.7 & 59.5 & 50.0 & 41.2 & 44.4 & 25.0 & 43.8 & & 52.3 \\
\hline
\end{tabular}

Overall, the fraction of fertile eggs was $90 \%$ during this study (egg 1, 89\%; egg 2, 91\%). In total, 239 clutches of two fertile eggs with known laying order were produced (85.7\% of all nests, $n=279)$, resulting in 478 sexed embryos, of which $250(52.2 \%)$ were male. This number did not deviate from parity $\left(p_{\text {binom. }}=0.34\right)$. As in the Wood pigeon, the sex ratios of egg $1(48.54 \% \hat{\sigma} \hat{\sigma}, n=239)$ and egg $2(56.07 \%$ ठิે, $n=238)$ did not differ significantly from $50 \%$ (egg 1, $p_{\text {binom. }}=0.71$; egg $\left.2, p_{\text {binom. }}=0.07\right)$. Likewise, sex ratio of egg 1 and egg 2 did not differ significantly from each other $\left(G_{1}=2.72, p=0.10\right)$.

As in the Wood pigeon data, the overall frequency of the

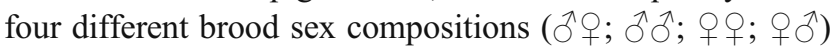
did not differ from random $\left(G_{3}=4.80, p=0.10\right.$, Table 3$)$. We even observed a non-significant trend in another direction than claimed in the literature: The brood composition of two males occurred most frequently, whereas the combination of a male in the first egg and a female in the second egg occurred less frequently (Table 3 ).

As in the Wood pigeon, a relation between sex ratio and laying date was evident. Monthly average sex ratio of all first eggs and second eggs combined ( $n=478$ embryos) showed a male bias during spring and a female bias during autumn (Table 3). Analyzing this variation in the course of the whole year, we applied harmonic regression (see "Materials and methods"), assuming a 12-month cycle period in sex ratio, and entering sine- and cosine-transformed laying month as predictor variables. This two-level model (pair and nest number) significantly explained embryonic sex ratio variation in the course of the year (laying month) in our experimental population (Wald $\chi_{2}{ }^{2}=11.628, p=0.003$, Table 3). The annual pattern amongst first eggs was significantly different from the variation observed in second eggs (Table 4 (including egg 1 and 2): interaction egg number $\times$ sine-transformed month of laying, $p=0.001$; fitted curves depicted in Fig. 2). Analyzing both eggs of the clutch separately, only the first egg showed clear, pronounced annual variation in sex ratio (Table 4 (only egg 1 included) and Fig. 2), whereas embryos of second eggs showed no significant annual variation in sex ratio (Table 4 (only egg 2 included), Fig. 2).

In order to discriminate between two potential interpretations of these results, i.e., intra-female manipulation or inter-female variation of the sex ratio, we applied the same analysis as presented in Table 4 , but now in a subsample of 15 out of 24 females which produced clutches not only during the months where egg 1 was male biased (MarchJune, see Fig. 2) but also during the months showing a female bias (August-November). Again, in this subsample ( $n=392$ out of 478 eggs), the clear annual variation in sex ratio was only present in egg 1 and not in egg 2 (interaction egg number $\times$ sine-transformed month of laying, $n=392$, Wald $\left.\chi_{1}^{2}=11.5, p<0.001\right)$. This result indicates that the annual variation of the sex ratio in Rock pigeons is due to intra-female manipulation and cannot be explained by interindividual co-variation of laying date and egg sex.

\section{Discussion}

We investigated the relation between laying date, the position of the egg in the laying sequence, and offspring sex ratio in two closely related avian species, the Wood pigeon and the Rock pigeon.

In the first place, we tested the hypothesis that offspring sex ratio varies over the year in accordance with sex differences in age of first reproduction (Dijkstra et al. 1990; Daan et al. 1996). According to this hypothesis, offspring sex ratios should change with laying date when both sexes differ in maturation time. We predicted that male pigeons, requiring more time till first reproduction than females (Johnston and Janiga 1995), should be produced in excess early in the peak reproductive season (spring-summer), when they have sufficient time to be a successful recruit next year. Females, who are recruited in the breeding population on average 1 month younger than males (Johnston and Janiga 1995), 
Table 4 Fitted parameters of a three-level (pair-nest-egg) model predicting Rock pigeon embryonic sex ratio (logit link function) for both eggs of the clutch as laid (egg number 1 or 2), assuming circannual cyclic variation of sex ratio, i.e., with a period of 12 months; additionally, the results are presented separately for egg 1 (showing significant circannual sex ratio variation), respectively, egg 2 (no significant circannual variation), based on two-level models (pair-nest)

\begin{tabular}{|c|c|c|c|}
\hline Predictors & $B$ (coeff.) & Wald $\chi_{1}^{2}$ & $p$ \\
\hline \multicolumn{4}{|l|}{ Including egg 1 and $2(n=478)$} \\
\hline Constant & -0.877 & & \\
\hline $\mathrm{A}=$ sine $(2 \times$ pi $\times$ month of laying $/ 12)$ & 1.834 & 15.189 & 0.0001 \\
\hline $\mathrm{B}=$ cosine $(2 \times$ pi $\times$ month of laying $/ 12)$ & -0.874 & 2.878 & n.s., 0.0898 \\
\hline $\mathrm{C}=$ egg number $(1$ or 2$)$ & 0.613 & 6.428 & 0.0112 \\
\hline $\mathrm{A} \times \mathrm{C}$ & -0.942 & 10.75 & 0.0010 \\
\hline $\mathrm{B} \times \mathrm{C}$ & 0.285 & 0.815 & n.s., 0.3681 \\
\hline \multicolumn{4}{|l|}{ Only egg 1 included $(n=239)$} \\
\hline Constant & -0.427 & & \\
\hline $\mathrm{A}=$ sine $(2 \times$ pi $\times$ month of laying $/ 12)$ & 0.815 & 14.311 & 0.0002 \\
\hline $\mathrm{B}=$ cosine $(2 \times$ pi $\times$ month of laying $/ 12)$ & -0.540 & 5.252 & 0.0219 \\
\hline \multicolumn{4}{|l|}{ Only egg 2 included $(n=239)$} \\
\hline Constant & 0.133 & & \\
\hline $\mathrm{A}=$ sine $(2 \times$ pi $\times$ month of laying $/ 12)$ & -0.045 & 0.051 & n.s., 0.8213 \\
\hline $\mathrm{B}=\operatorname{cosine}(2 \times$ pi $\times$ month of laying $/ 12)$ & -0.277 & 1.579 & n.s., 0.2089 \\
\hline
\end{tabular}

Cyclicity of the data was tested by harmonic modeling using a linear version of a sine wave (see "Materials and methods"). For fitted curves based on this model, see Fig. 2. The significant interaction between egg number and (sine-transformed) laying month shows that circannual variation in sex ratio varies significantly between egg 1 and 2

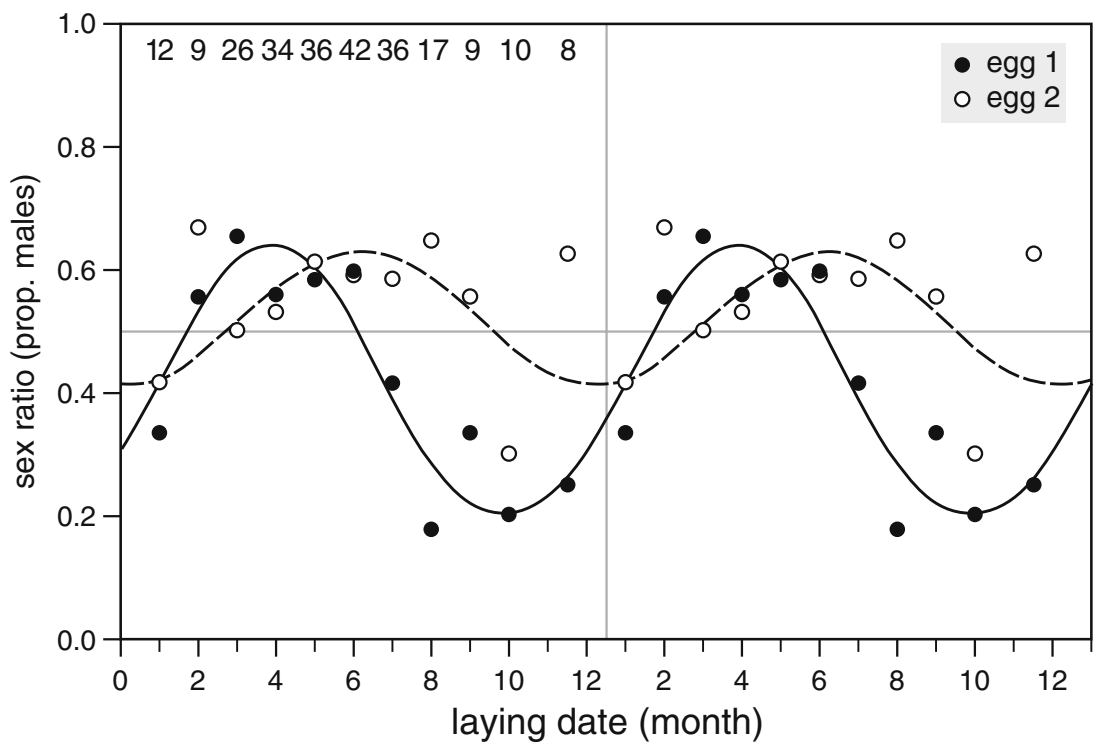

Fig. 2 Double plot (right panel is a copy of the data presented in the left panel) of sex ratios (proportion males) in the course of the year in 239 Rock pigeon clutches of two eggs collected after 3 days of incubation ( $n=478$ embryos). Data are presented separately for first (solid lines, black dots) and second eggs (dashed lines, white dots) within the clutch. Symbols represent monthly averages. For the figure, the data of November and December were pooled due to small sample sizes. The lines represent, for eggs 1 and 2 separately, the fit of a model accounting for circannual variation in sex ratio (assuming a period of 12 months, see "Materials and methods"). The numbers refer to the sample size per month (number of clutches=number of first eggs $=$ number of second eggs) 
were expected to be in the majority among young born later in the year. These predicted sex biases in the course of the year were indeed observed in this study for first eggs. The results were remarkably similar between the two Columba species, indicating a robust phenomenon. This suggests that sex ratio manipulation in relation to sex differences in maturation time as an adaptive strategy to maximize fitness is a sound ultimate explanation for pigeons (see also Edmunds and Ankney 1987), as it is for kestrels (Dijkstra et al. 1990; Daan et al. 1996; Smallwood and Smallwood 1998; Pen et al. 1999).

In both species, there was no overall sex ratio bias apparent and no overall effect of the position of the egg in the laying sequence, but it was only the sex of the first egg that is affected by laying date, with a strong male bias in spring. In the course of the year, this male bias shifted towards a female bias in both the Wood pigeon and the Rock pigeon. The stronger fluctuation in the proportion of males in first eggs in the Rock pigeon relative to the Wood pigeon might be simply explained by the year-round laying of the Rock pigeon. In the Rock pigeons, the observed sex ratio variation was apparently controlled by an annual rhythm, i.e., with a cycle period of 12 months. This is, to our knowledge, the first avian study showing an annual rhythm in the sex of the offspring produced. This pattern was independent of food as the birds were fed ad libitum. Since the study was carried out outdoors, the birds were exposed to variation in both day length and ambient temperature. These factors may well be used by the pigeons as temporal cues to take these reproductive decisions. Alternatively, these decisions may be based upon an endogenous program, such as is involved in the control of seasonal variation in clutch size in the kestrel (Meijer et al. 1990). Studies in constant conditions of day length and temperature will be required to address this possibility.

Our research was also inspired by claims in the literature on pigeon offspring sex ratio variation that have already been made more than two millennia ago (Aristotle 350 B.C.) but that have not been sufficiently supported by empirical data. Despite the proposition, repeatedly mentioned in the literature, that pigeons produce a majority of sons in first eggs and daughters in second eggs (e.g., Aristotle 350 B.C.; Darwin 1874, p. 263; Starr 1886; Fulton and Lumley 1895 p. 38; Riddle 1919), we could not find convincing evidence for this. The frequency of this brood composition (male first, female second) did not occur more often than expected on the basis of a random distribution of sex combinations when all clutches over the whole season were combined. The sex ratio of first eggs did not statistically differ from second eggs, and both did not differ from $50 \%$. In the Wood pigeon, the difference in sex ratio between both nestlings (rank 1 vs rank 2) showed a non-significant trend into the direction predicted in the literature. This may be related to the interaction between nestling rank and laying date in sex ratio variation. In spring, the Wood pigeon data indeed showed a male bias among nestlings of rank 1 and a female bias among nestlings of rank 2. Although this pattern was reversed in autumn, most clutches are produced in spring, inducing an overall non-significant pattern in the direction suggested by Aristotle.

The observed decrease in sex ratio in the course of the year may well be induced by repeated re-laying of the females in the Rock pigeon, caused by our egg removal scheme, and possibly also in the Wood pigeon, where natural nest predation and re-laying of several replacement clutches in the course of the year are common (Murton and Westwood 1977). In both species, repeated re-laying during the peak reproductive season may result in reduced maternal body condition during autumn, at a time when also the energy demands for molt are high (Johnston and Janiga 1995). If so, our results are in line with experimental evidence on food restriction in homing pigeons, which reduces maternal body condition, and results in femalebiased offspring after repeated re-laying (Pike 2005).

In both species, laying date significantly affected only the sex of the first egg and not the second egg. With respect to the mechanism causing this bias, this is consistent with the suggestion by Emlen (1997), that especially in species with small clutch sizes (such as pigeons), the sex of the first egg can be manipulated by the mother, for instance, by means of aborting the follicle bearing the unwanted sex. Such manipulation of first eggs only would prevent potentially detrimental effects of laying gaps between successive eggs of the clutch or reduced yolk mass (see "Introduction"). Our data are also in agreement with other recent studies on domestic pigeons, reporting several experimental manipulations that induce a deviation in sex ratio in first eggs only (Pike 2005; Goerlich et al. 2009; Goerlich et al., unpublished data; Müller et al., unpublished data). These data suggest that the biased sex ratios we found in first eggs could theoretically be achieved by follicle abortion. Although Pike (2005) suggested follicle abortion to underlie the sex ratio skew in second eggs as well, statistical re-analysis of his data could not confirm a significant effect of his treatment on the sex of the second egg (Goerlich et al. 2009). Although the sex bias in first eggs is consistent with the idea of sex-specific follicle abortion, such a mechanism would require additional developed follicles to replace the first follicle in case of abortion. Autopsies of over a hundred egg-laying female domestic pigeons did not provide evidence for the presence of more than two developed follicles (Goerlich et al., unpublished data). This warrants a search for alternative mechanisms. Postovulatory mechanisms are unlikely: Resorption of already ovulated eggs would hamper the transfer of the next egg in the oviduct, leading to extreme 
delays in laying which we can exclude to a large extent since we usually checked nests on a daily basis. Sexspecific fertilization rates or sex-specific embryo mortality would have induced high frequencies of eggs without visible embryo development, which we did not find. Therefore, it is likely that a preovulatory mechanism is in place. This may be the non-random segregation of female sex chromosomes or "meiotic drive," for which there is some evidence in birds (Rutkowska and Badyaev 2008; Badyaev et al. 2008).

In conclusion, our results support the hypothesis that offspring sex ratio is adaptively adjusted on a seasonal basis to sex-specific differences in maturation time, most likely by preovulatory mechanisms. Persistent claims in the literature about overall sex ratio skews in pigeons are not supported. To our knowledge, the Rock pigeon study provides the first evidence of a full annual rhythm in adaptive sex allocation in birds.

Acknowledgements We thank all the owners permitting us to collect the Wood pigeon data on their property. We are grateful for the help of many students who were involved in the Rock pigeon study. We thank the animal caretakers Sjoerd Veenstra, Roelie Veenstra-Wiegman, Saskia Helder, and Monique Huizinga for taking care of the Rock pigeons. We gratefully acknowledge the assistance of Guido Meeuwissen, Bonnie de Vries, and Roelie Veenstra-Wiegman in the DNA lab with the molecular sex determinations. We thank Nicolaus von Engelhardt and Roelof Hut for their great help with the statistics, and Dick Visser for promoting the layout of the figures. Finally, we acknowledge the suggestions made by three anonymous referees, which greatly improved the manuscript. This project was approved by the Animal Experimentation Committee of the University of Groningen under license DEC 2682. The authors were supported by grants from the University of Groningen (CD, VCG), NWO (BR, TGGG), and EU (FP6 018741 EUCLOCK; SD).

Conflict of interest The authors declare that they have no conflict of interest.

Open Access This article is distributed under the terms of the Creative Commons Attribution Noncommercial License which permits any noncommercial use, distribution, and reproduction in any medium, provided the original author(s) and source are credited.

\section{References}

Alonso-Alvarez C (2006) Manipulation of primary sex-ratio: an updated review. Avian Poul Biol Rev 17:1-20

Andersson M, Wallander J, Oring L, Akst E, Reed JM, Fleischer RC (2003) Adaptive seasonal trend in brood sex ratio: test in two sister species with contrasting breeding systems. J Evol Biol $16: 510-515$

Ankney CD (1982) Sex-ratio varies with egg sequence in lesser snow geese. Auk 99:662-666

Aristotle (ca. 350 B.C.) History of animals. Book VI. p. 885. In: Barnes J (ed) The complete works of Aristotle. The revised Oxford Translation. Vol 1(2), (1984). Bollingen Series 71:2. Princeton University Press (ISBN: 0691099502)
Arnold KE, Griffiths R (2003) Sex-specific hatching order, growth rates and fledging success in jackdaws Corvus monedula. J Avian Biol 34:275-281

Badyaev AV, Hill GE, Beck ML (2003) Interaction between maternal effects: onset of incubation and offspring sex in two populations of a passerine bird. Oecologia 135:386-390

Badyaev AV, Young RL, Hill GE, Duckworth RA (2008) Evolution of sex-biased maternal effects in birds. IV. Intra-ovarian growth dynamics can link sex determination and sex-specific acquisition of resources. J Evol Biol 21:449-460

Carranza J (2004) Sex allocation within broods: the intrabrood sharing-out hypothesis. Behav Ecol 15:223-232

Cole LJ, Kirkpatrick WF (1915) Sex ratios in pigeons, together with observations on laying incubation and hatching of eggs. R I Agr Exp Stat Bull A 162:462-512

Comas M, Beersma DGM, Hut RA, Daan S (2008) Circadian phase resetting in response to light-dark and dark-light transitions. J Biol Rhythms 23:425-434

Daan S, Dijkstra C, Weissing FJ (1996) An evolutionary explanation for seasonal trends in avian sex ratios. Behav Ecol 7:426430

Darwin C (1874) The descent of man and selection in relation to sex. David McKay, Philadelphia, First ed. publ. 1871

Dijkstra C, Daan S, Buker JB (1990) Adaptive seasonal-variation in the sex-ratio of kestrel broods. Funct Ecol 4:143-147

Edmunds SR, Ankney CD (1987) Sex-ratios of hatchling mourning doves. Can J Zool 65:871-874

Emlen ST (1997) When mothers prefer daughters over sons. Trends Ecol Evol 12:291-292

Eraud C, Lallemand J, Lormee H (2006) Sex-ratio of Skylark Alauda arvensis broods in relation to timing of breeding. Bird Study 53:319-322

Fulton R, Lumley WF (1895) Fulton's book of pigeons. Cassel \& Co. Ltd, London

Goerlich VC, Dijkstra C, Schaafsma SM, Groothuis TGG (2009) Testosterone has a long-term effect on primary sex ratio of first eggs in pigeons-in search of a mechanism. Gen Comp Endocrinol 163:184-192

Goldstein H (1995) Multilevel statistical models. Arnold, London

Griffiths R, Daan S, Dijkstra C (1996) Sex identification in birds using two CHD genes. Proc R Soc Lond B Biol Sci 263:12511256

Griffiths R, Double MC, Orr K, Dawson RJG (1998) A DNA test to sex most birds. Mol Ecol 7:1071-1075

Hardy ICW (2002) Sex ratios: concepts and research methods. Cambridge University Press, Cambridge

Howe HF (1977) Sex ratio adjustment in the common Grackle. Science 198:744-745

Husby A, Saether BE, Jensen H, Ringsby TH (2006) Causes and consequences of adaptive seasonal sex ratio variation in house sparrows. J Anim Ecol 75:1128-1139

Johnston RF, Janiga M (1995) Feral pigeons. Oxford University Press, New York

Jones KS, Nakagawa S, Sheldon BC (2009) Environmental sensitivity in relation to size and sex in birds: meta-regression analysis. Am Nat $174: 122-133$

Levi WM (1945) The pigeon. Bryan, Columbia

Lezalova R, Tkadlec E, Obornik M, Simek J, Honza M (2005) Should males come first? The relationship between offspring hatching order and sex in the black-headed gull Larus ridibundus. J Avian Biol 36:478-483

Lincoln GA, Clarke IJ, Hut RA, Hazlerigg DG (2006) Characterizing a mammalian circannual pacemaker. Science 314:1941-1944

Meijer T, Daan S, Hall M (1990) Family planning in the kestrel (Falco tinnunculus): the proximate control of covariation in clutch size and laying date. Behaviour 114:117-136 
Murton RK, Westwood NJ (1977) Avian breeding cycles. Oxford University Press, New York

Nager RG, Monaghan P, Houston DC, Genovart M (2000) Parental condition, brood sex ratio and differential young survival: an experimental study in gulls (Larus fuscus). Behav Ecol Sociobiol 48:452-457

Oguma K (1927) Studies on the Sauropsid chromosomes. I. The sexual difference of chromosomes in the pigeon. J Coll Agr Hokkaido Imp Univ 16:203-227

Pen I, Weissing FJ, Daan S (1999) Seasonal sex ratio trend in the European kestrel: an evolutionary stable strategy analysis. Am Nat 153:384-397

Pike TW (2005) Sex ratio manipulation in response to maternal condition in pigeons: evidence for pre-ovulatory follicle selection. Behav Ecol Sociobiol 58:407-413

Pike TW, Petrie M (2003) Potential mechanisms of avian sex manipulation. Biol Rev 78:553-574

Rasbash J, Steele F, Browne W, Prosser B (2005) A user's guide to MLwiN-Version 2.0. Centre for Multilevel Modelling, University of Bristol, Bristol

Riddle O (1919) Posthumous works of Charles Otis Whitman. II. Inheritance, fertility and the dominance of sex and color in hybrids of wild species of pigeons. Carnegie Institution, Washington

Rutkowska J, Badyaev AV (2008) Review. Meiotic drive and sex determination: molecular and cytological mechanisms of sex ratio adjustment in birds. Philos Trans R Soc Lond B Biol Sci 363:1675-1686

Smallwood PD, Smallwood JA (1998) Seasonal shifts in sex ratios of fledgling American kestrels (Falco sparverius paulus): the early bird hypothesis. Evol Ecol 12:839-853

Starr ES (1886) The breeding of fancy pigeons. Cent Illus Mon Mag 32:94-107

Trivers RL, Willard DE (1973) Natural-selection of parental ability to vary sex-ratio of offspring. Science 179:90-92

Walsh PS, Metzger DA, Higuchi R (1991) Chelex-100 as a medium for simple extraction of DNA for PCR-based typing from forensic material. Biotechniques 10:506-513

Weatherhead PJ (2009) Multi-year seasonal sex-allocation patterns in red-winged blackbirds (Agelaius phoeniceus). Auk 126:181185

Wingfield JC, Farner DS (1993) Endocrinology of reproduction in wild species. In: Farner DS, King JR, Parkes KC (eds) Avian biology. Academic, London, pp 163-327 